\title{
Morphological analysis of fractures of the ulnar coronoid process
}

\begin{abstract}
Background: Coronoid fractures are most commonly classified by the Regan-Morrey and by the O'Driscoll classifications. O'Driscoll emphasized the importance of anteromedial facet fractures with use of computer tomography (CT) scans. However, this classification did not address lateral fractures. Adams et al classified anterolateral oblique fracture recently. The aim of this study was to perform a radiologic examination of coronoid fractures and to evaluate the importance of lateral coronoid fractures. We hypothesized that lateral coronoid fractures would be more common in terrible triad injuries than has been previously reported.
\end{abstract}

Methods: Thirty-five coronoid fractures were appropriate for investigation. Twenty-two men and 13 women with an average age of 41 years (range, 14-74 years) who had a mean follow-up of 8.6 months (range, 1-30 months) were enrolled. Thirty-three cases were fracture-dislocations ( 11 terrible triad injuries) and 2 cases were isolated coronoid fractures. Using radiologic evaluations, we assessed for medial or lateral fractures, the height of the fracture fragments, and the ReganMorrey and O'Driscoll classifications.

Results: There were 22 cases of medial (63\%) and 10 cases of lateral fractures (29\%), and 3 cases were undeterminable (8\%). The average height of the coronoid fracture fragments was $6.5 \mathrm{~mm}$ (range, 2-14 mm). There were 11-terrible triad injuries, there 7 of which were medial and 4 of which were lateral fractures.

Conclusion: There were more medial coronoid fractures than lateral overall, and the same trend was observed in terrible triad injuries, which was contrary to our hypothesis. However, there were more lateral fractures than reported previously.

Level of evidence: Level $\beta$, Retrospective Cohort Design; Treatment Study.

Keywords: coronoid, coronoid fracture, elbow fracture-dislocation, terrible triad injury, regan-morrey classification, $o^{\prime}$ driscoll classification

\section{Introduction}

The coronoid process of the ulna is recognized as the keystone against posterior dislocation. Fractures of the coronoid rarely occur as isolated injuries, and frequently occur in association with posterior elbow dislocations. Coronoid fractures have traditionally been classified by the Regan-Morrey [1] classification, which is based on the size of the fracture fragments on lateral plain radiographs. In 2003, O'Driscoll et al., [2] proposed a new classification for coronoid fractures based on anatomic location and size using computer tomography (CT) scans. They emphasized the importance of anteromedial facet (AMF) fractures, which can lead to varus posteromedial rotational instability (VPMRI) of the elbow. However, this classification does not include lateral coronoid fractures. Lateral coronoid fractures had been reported in the past $[3,4]$ and are not rare. The purpose of this study was to investigate the radiologic findings of coronoid fractures and to evaluate the fracture patterns and the importance of lateral coronoid fractures. We examined the radiologic findings of all coronoid fractures, classified them into medial and lateral types, and evaluated the outcome of both types. Almost all the coronoid fractures were elbow fracture-dislocations, while terrible triad injuries accounted for $1 / 3$ of the injuries. We hypothesized that lateral coronoid fractures would be more common in the case of the terrible triad injuries, which consist of an elbow dislocation and fractures of the coronoid and radial head. This is because the force in
Ryuji Koga ${ }^{1 *}$, Shohei Iwabu², Kozo Furushima ${ }^{1}$, Hiroshi Kusano ${ }^{1}$, Yoshiyasu Itoh ${ }^{1}$

${ }^{1}$ Keiyu Orthopaedic Hospital, 1741 Hanetsuku, Tatebayashi, Gunma 3740011, Japan

${ }^{2}$ Saiseikai Utsunomiya Hospital, Utsunomiya, Japan

*Author for correspondence:

ryuji-koga@ku-kai.or.jp 
a posterior dislocation is directed more in a lateral direction and would theoretically lead to a lateral fracture of the coronoid by the same mechanism as the bony Bankart lesion in a shoulder dislocation.

\section{Materials and Methods}

This retrospective study involved data for patients who were treated at our institution for elbow fracture-dislocations and coronoid fractures, and was approved by our institutional review board. Informed consent was obtained for experimentation with human subjects. Fiftyfour patients were surgically treated for elbow fracture-dislocations between April 2006 and December 2016. Of these 54 cases, 33 cases (61\%) had accompanying coronoid fractures, and 2 patients were treated with isolated coronoid fractures in the same period. Thus, 35 cases were included in this study (TABLE 1).

TABLE 1. Summary of patient data.

\begin{tabular}{|c|c|c|c|c|c|c|c|c|c|c|}
\hline Case & $\begin{array}{l}\text { S e } x \\
\text { age }\end{array}$ & Side & Mechanism & $\begin{array}{l}\text { Complicated } \\
\text { injuries }\end{array}$ & $M / L$ & it & R-M & O'Driscoll & $\begin{array}{l}F u \\
\text { (M) }\end{array}$ & MEPS \\
\hline 1 & $M / 28$ & L & Fall & $\begin{array}{l}\text { RHF,OF,MCL,LCL } \\
\text { injury }\end{array}$ & L & $9 / 20(45 \%)$ & Type2 & Type3-1 & 18 & 85 \\
\hline 2 & $M / 14$ & $\mathrm{R}$ & Sports & $\begin{array}{l}\text { Capitellum } \\
\text { fracture }\end{array}$ & $M$ & 9/21(43\%) & Type2 & Type2-2 & 11 & 100 \\
\hline 3 & M/19 & L & Sports & MCL,LCLinjury & $\mathrm{L}$ & $10 / 25(40 \%)$ & Type2 & Type3-1 & 5 & 100 \\
\hline 4 & $F / 74$ & $\mathrm{~L}$ & Fall & MCL,LCLinjury & $M$ & $12 / 23(52 \%)$ & Type3 & Type3-1 & 30 & 85 \\
\hline 5 & $M / 36$ & $\mathrm{~L}$ & Sports & MCL,LCLinjury & $\mathrm{L}$ & $10 / 25(40 \%)$ & Type2 & Type3-1 & 7 & 100 \\
\hline 6 & $F / 54$ & L & Fall & $\begin{array}{l}\text { RHF, MCL, LCL } \\
\text { injury }\end{array}$ & $M$ & $5 / 20(25 \%)$ & Type1 & Type2-1 & 8 & 100 \\
\hline 7 & $M / 46$ & $\mathrm{R}$ & Fall & MCL,LCLinjury & $M$ & $3 / 20(15 \%)$ & Type1 & Type1-2 & 4 & 100 \\
\hline 8 & $M / 29$ & $\mathrm{R}$ & Sports & MCL,LCLinjury & $\mathrm{L}$ & $8 / 18(44 \%)$ & Type2 & Type3-1 & 1 & N/A \\
\hline 9 & $M / 52$ & L & Fall & RHF,MCLinjury & $M$ & $9 / 20(45 \%)$ & Type2 & Type2-2 & 13 & 100 \\
\hline 10 & $F / 63$ & L & Fall & RHF,OF & $M$ & UD & Type3 & Type3-2 & 9 & 100 \\
\hline 11 & $M / 17$ & $\mathrm{R}$ & Fall & MCF,LCL injury & L & $4 / 16(25 \%)$ & Type1 & Type1-2 & 5 & 100 \\
\hline 12 & $M / 42$ & $\mathrm{R}$ & Fall & RHF,MCL injury & $M$ & 10/23(43\%) & Type2 & Type2-3 & 3 & 100 \\
\hline 13 & $M / 23$ & L & Sports & MCLinjury & M & $8 / 20(40 \%)$ & Type2 & Type2-1 & 5 & 100 \\
\hline 14 & $F / 29$ & $\mathrm{R}$ & Fall & $\begin{array}{l}\text { RHF, MCL, LCL } \\
\text { injury }\end{array}$ & $\mathrm{L}$ & $4 / 17(24 \%)$ & Type1 & Type1-2 & 18 & 85 \\
\hline 15 & $M / 15$ & $\mathrm{R}$ & Sports & & $M$ & $7 / 16(44 \%)$ & Type2 & Type2-2 & 7 & 100 \\
\hline 16 & $F / 67$ & L & Fall & & M & $4 / 17(24 \%)$ & Type1 & Type2-2 & 28 & 100 \\
\hline 17 & $F / 63$ & $\mathrm{R}$ & Fall & $\mathrm{RHF}, \mathrm{OF}$ & UD & UD & Type3 & Type3-2 & 5 & 100 \\
\hline 18 & $M / 22$ & L & Sports & MCL,LCLinjury & $M$ & $4 / 21(19 \%)$ & Type1 & Type2-1 & 1 & N/A \\
\hline 19 & $F / 19$ & $\mathrm{R}$ & Sports & MCL injury & $M$ & $8 / 28(29 \%)$ & Type1 & Type2-2 & 10 & 100 \\
\hline 20 & $F / 67$ & L & Fall & MCL,LCLinjury & L & $2 / 20(10 \%)$ & Type1 & Type2-2 & 5 & 100 \\
\hline 21 & $F / 39$ & $\mathrm{~L}$ & Fall & MCL,LCLinjury & $M$ & $3 / 23(13 \%)$ & Type1 & Type2-2 & 1 & N/A \\
\hline 22 & $M / 16$ & L & Sports & MCL,LCLinjury & $M$ & $5 / 29(17 \%)$ & Type1 & Type2-2 & 4 & 100 \\
\hline 23 & $M / 51$ & L & Fall & OF,LCL injury & UD & UD & Type3 & Type3-2 & 6 & 80 \\
\hline 24 & $M / 46$ & $\mathrm{R}$ & Fall & LCL injury & $M$ & UD & Type3 & Type3-1 & 6 & 100 \\
\hline 25 & $M / 60$ & $\mathrm{R}$ & Fall & MCL,LCLinjury & M & $2 / 25(8 \%)$ & Type1 & Type2-3 & 12 & 100 \\
\hline 26 & $F / 37$ & $\mathrm{~L}$ & Sports & RHF,LCL injury & $M$ & $5 / 25(20 \%)$ & Type1 & Type2-2 & 1 & N/A \\
\hline 27 & $M / 58$ & $\mathrm{R}$ & Fall & OF & UD & UD & Type3 & Type3-2 & 13 & 100 \\
\hline 28 & $F / 72$ & $\mathrm{R}$ & Fall & RHF,LCL injury & $M$ & $8 / 24(33 \%)$ & Type2 & Type2-2 & 12 & 100 \\
\hline 29 & $M / 42$ & L & Fall & RHF,LCL injury & L & $5 / 24(21 \%)$ & Type2 & Type2-2 & 16 & 85 \\
\hline 30 & $F / 34$ & $\mathrm{R}$ & Fall & MCL,LCLinjury & $M$ & $10 / 28(36 \%)$ & Type2 & Type2-3 & 6 & 80 \\
\hline 31 & $M / 28$ & L & Fall & LCL injury & L & $4 / 28(14 \%)$ & Type1 & Type2-2 & 12 & 85 \\
\hline 32 & $\mathrm{M} / 40$ & L & Fall & $\begin{array}{l}\text { RHF, MCL, LCL } \\
\text { injury }\end{array}$ & L & $5 / 25(20 \%)$ & Type1 & Type2-2 & 6 & 100 \\
\hline
\end{tabular}




\begin{tabular}{|l|l|l|l|l|l|l|l|l|l|l|}
\hline 33 & $\mathrm{~F} / 38$ & $\mathrm{R}$ & Fall & $\begin{array}{l}\text { RHF, MCL, LCL } \\
\text { injury }\end{array}$ & M & 2/20(10\%) & Type1 & Type1-1 & 4 & 70 \\
\hline 34 & $\mathrm{M} / 17$ & $\mathrm{R}$ & Sports & & $\mathrm{M}$ & UD & Type1 & Type2-1 & 5 & 100 \\
\hline 35 & $\mathrm{M} / 61$ & $\mathrm{~L}$ & Fall & & $\mathrm{M}$ & 14/22(64\%) & Type3 & Type3-1 & 4 & 100 \\
\hline
\end{tabular}

RHF, Radial head fracture; OF, Olecranon fracture; MCF, Medial condyle fracture; M, Medial side; L, Lateral side; UD, Undeterminable

R-M, Regan-Morrey classification; Fu, Follow up; MEPS, Mayo elbow performance score; N/A, Not available for follow-up

There were 22 men and 13 women, with an average age of 41 years (range, $14-74$ years) and a mean follow-up of 8.6 months (range, 1-30 months). On radiologic evaluation, we assessed the location of the coronoid fractures (medial or lateral type), the height of the fracture fragments, the Regan-Morrey classification, and the O'Driscoll classification. Postoperative functional evaluation was performed with the Mayo elbow performance score (MEPS) in 31 cases ( 4 cases were transferred to other hospitals), and the mean follow-up of these patients was 9.6 months (range, 3-30 months). CT was mainly used to classify the fractures as medial or lateral, and plain radiography was used when CT scans were not available (FIGURE 1). CT scans were not performed in 3 cases. We classified whether the fragment was medial or lateral from the midline of the ulna axis on the coronal view and judged basal fractures to be undeterminable. The height of the fracture fragments was measured with CT or lateral radiographs as described by Doornberg [5]. The base of the coronoid was selected as a line connecting a point at the base of the trochlear notch (TB) with a point at the anterior ulnar cortical margin (CM) distal to the coronoid process. The height of the unfractured coronoid was measured along a line perpendicular to the line defining the base of the coronoid process $(\mathrm{CH})$, and the fracture fragment was also measured along the apex of the trochlear notch. We calculated the ratio of the fragments to the total height of the coronoid (FIGURE 2) and judged basal fractures and shattered fragments to be undeterminable. Regan and Morrey classified coronoid fractures into 3 types: type 1 involves an avulsion of the tip of the coronoid process, type 2 involves $50 \%$ of the process or less, and type 3 involves more than $50 \%$ of the process. However, the definitions of type 1 and type 2 were unclear. We used a classification reported by Doornberg [5], in which, type 1 involves a tip fracture $<30 \%$ of the total height of the coronoid, type 2

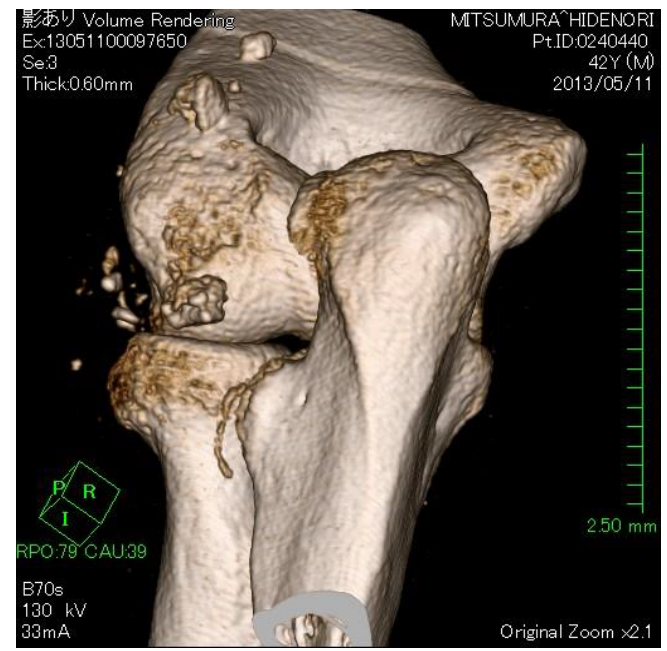

FIGURE 1. The coronoid fractures were divided into medial or lateral type from the midline of the ulnar bone axis (Red line) on coronal view. The yellow arrow was the coronoid fragment and fracture site. This case was defined as a lateral coronoid fracture.

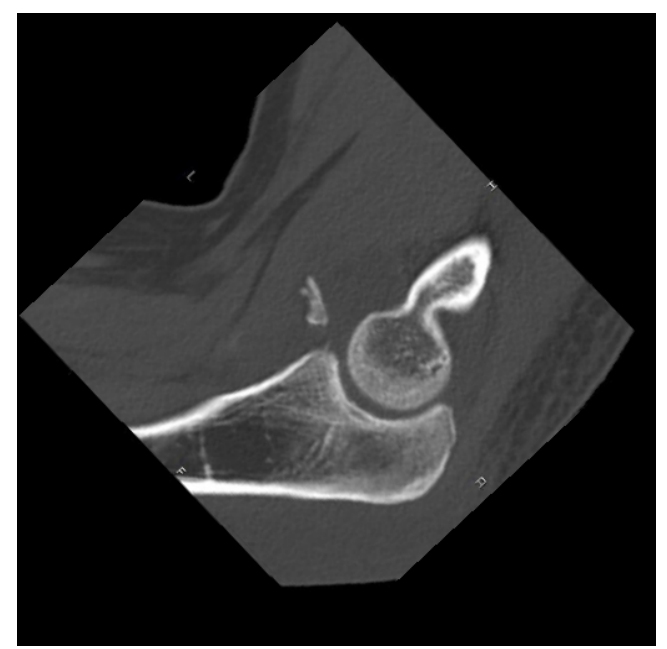

FIGURE 2. Measurement of coronoid height (CH). The base of the coronoid was selected as a line connecting a point at the base of the trochlear notch (TB) with a point at the anterior ulnar cortical margin (CM) distal to the coronoid process. (Fragment ratio $(\%)=a / a+b \times 100)$.

is a fracture between $30 \%$ and $50 \%$, and type 3 is a fracture $>50 \%$ of the total coronoid height. This was according to the interpretation by Schneeberger et al., [6], based on biomechanical 
studies. O'Driscoll classified coronoid fractures using CT scans as follows: type 1 involves a transverse fracture of the tip of the coronoid, type 2 is a fracture of the anteromedial facet, and type 3 involves a fracture of the base of the coronoid, with further classifications in detail for each subtype. In 3 cases CT scans were not performed, so their evaluations were performed with plain radiography or magnetic resonance imaging (MRI).

\section{Statistical Methods}

Statistical comparisons between the incidence of medial and lateral coronoid fractures with or without radial head fracture were performed with the Mann-Whitney U test. The comparisons of MEPS between the groups were performed with the Fisher's exact test.

\section{Results}

There were 22 medial (63\%) and 10 lateral (29\%) fractures, and 3 cases were undeterminable (8\%). The total height of the coronoid process of the ulna averaged $22.2 \mathrm{~mm}$ (range, 16-29 mm). The average height of the coronoid fracture fragments was $6.5 \mathrm{~mm}$ (range, $2-14 \mathrm{~mm}$ ). This corresponds to an average of $29.8 \%$ of the total height of the coronoid (range, 8-64\%). According to the Regan-Morrey classification, 16 cases were type 1 (46\%), 12 cases were type $2(34 \%)$, and 7 cases were type 3 (20\%). Under the O'Driscoll classification, 4 cases were type 1 (11\%), 20 cases were type 2 (57\%), and 11 cases were type 3 (32\%). According to the O'Driscoll classification, AMF fractures were defined as type 2 even if the fragment was small, so there were only a small number of type 1 fractures. Of the 11 coronoid fractures that had accompanying radial head fractures, there were 7 medial and 4 lateral coronoid fractures (TABLE 2). This result was contrary to our prior expectations. Of the 21 other cases without a radial head fracture (3 cases were undeterminable), there were 15 medial and 6 lateral coronoid fractures. A statistically significant association was not found between medial and lateral coronoid fractures with radial head fractures $(\mathrm{P}=0.12$, MannWhitney $U$ test). The average MEPS was 94.8 points (range, 70-100 points). The outcomes of the 4 patients with lateral coronoid plus radial head fractures were relatively unsatisfactory (TABLE 2). However, there were no significant differences in clinical outcomes between the groups ( $\mathrm{P}=0.79$, Fisher's exact test).

\section{Case Presentation}

Case 28: A 72-year-old woman was injured by a fall. An X-ray demonstrated the so-called terrible triad injury (FIGURE 3). The coronoid fracture was medial, the height of the fragment was $8 \mathrm{~mm}$, and the total height of the coronoid process was $24 \mathrm{~mm}$. Thus, the ratio of the fragment to the total height was $33 \%$. The fracture was classified as type 2 according to both the Regan-Morrey and O'Driscoll classifications.

TABLE 2. Coronoid fracture details with a focus on RHF.

\begin{tabular}{|c|c|c|c|c|c|c|}
\hline \multirow{3}{*}{ RHF } & \multicolumn{4}{|c|}{ Fracture dislocations (30) } & \multirow{2}{*}{$\begin{array}{c}\text { Isolated } \\
\text { fracture (2) } \\
N(2)\end{array}$} & \multirow{2}{*}{$\begin{array}{c}\text { Undeterminable } \\
\text { (3) } \\
Y(1) N(2)\end{array}$} \\
\hline & \multicolumn{2}{|c|}{$Y(11)$} & \multicolumn{2}{|c|}{ N (19) } & & \\
\hline & Medial (7) & Lateral (4) & Medial (13) & $\begin{array}{c}\text { Lateral } \\
\text { (6) }\end{array}$ & Medial (2) & \\
\hline \multicolumn{7}{|l|}{ R-M } \\
\hline Type 1 & 3 & 2 & 7 & 3 & 1 & \\
\hline Type 2 & 3 & 2 & 4 & 3 & & \\
\hline Type 3 & 1 & & 2 & & 1 & 3 \\
\hline \multicolumn{7}{|c|}{ O'Driscoll } \\
\hline Type 1 & 1 & 1 & 1 & 1 & & \\
\hline Type 2 & 5 & 2 & 10 & 2 & 1 & \\
\hline Type 3 & 1 & 1 & 2 & 3 & 1 & 3 \\
\hline \multirow[t]{2}{*}{ MEPS } & 92.5 & 88.8 & 96.8 & 97 & 100 & 93.3 \\
\hline & $(70-100)$ & $(85-100)$ & $(80-100)$ & $(85-100)$ & & $(80-100)$ \\
\hline
\end{tabular}



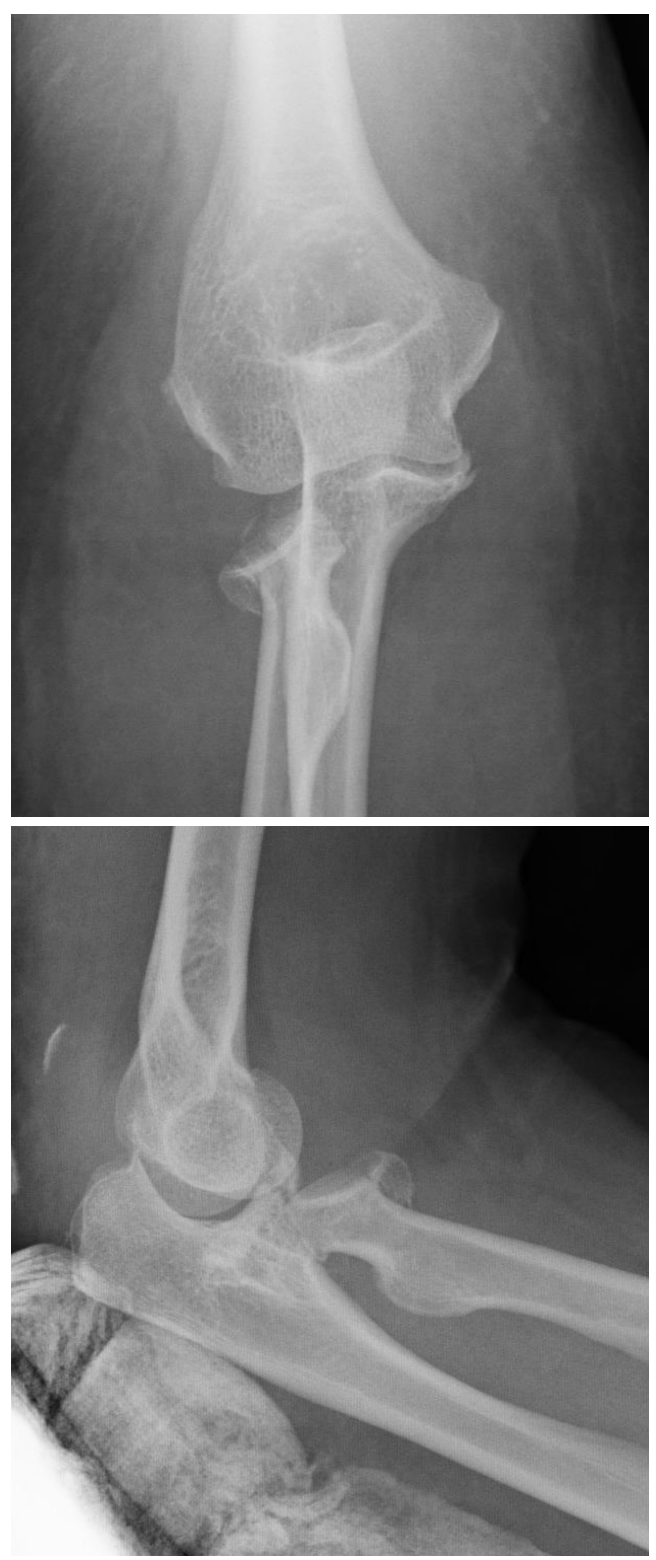

FIGURE 3. Case28: 72-year-old woman. The socalled "terrible triad injury". The coronoid fracture was medial, and was a type $\mathbf{2}$ fracture in the ReganMorrey and O'Driscoll classifications.
Lateral collateral ligament (LCL) repair and plate fixation of the radial head fracture was performed, and the coronoid fracture was fixed with a suture lasso technique (FIGURE 4a, b) [7]. Twelve months after surgery, the arc of elbow motion was $140^{\circ}\left(0-140^{\circ}\right)$, and she had no instability or pain. The MEPS was 100 points.

Case 14: A 29-year-old woman was injured by a fall. An X-ray showed a terrible triad injury (FIGURE 5a, b). The coronoid fracture was lateral, the height of the fragment was $4 \mathrm{~mm}$, and the total height of a coronoid process was $17 \mathrm{~mm}$. Therefore, the ratio of the fragment to the total height was $24 \%$. The fracture was classified as type 1 according to both the ReganMorrey and O'Driscoll classifications. Medial collateral ligament (MCL) and LCL repair and screw fixation of the radial head fracture was performed, and the coronoid fracture was not fixed (FIGURE 6a, b). Eighteen months after surgery, the arc of elbow motion was $90^{\circ}$ (flexion $120^{\circ}$, extension $\left.-30^{\circ}\right)$. She had no instability or pain, but she had difficulty with combing her hair and putting on a shirt. The MEPS was 85 points.

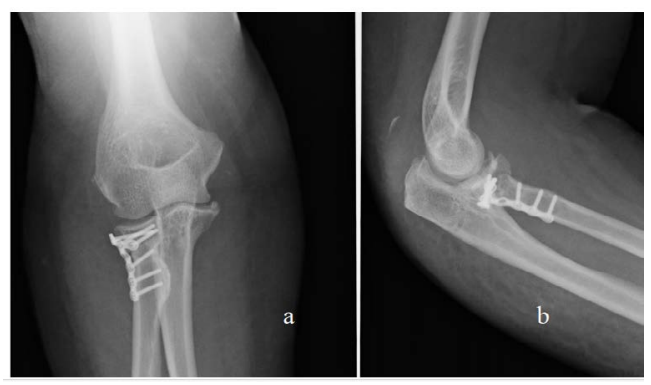

FIGURE 4. Lateral collateral ligament (LCL) repair and plate fixation of the radial head fracture was performed, and the coronoid fracture was fixed with lasso technique. Twelve months after surgery, the arc of elbow motion was $140^{\circ}$ and MEPS was 100 points.

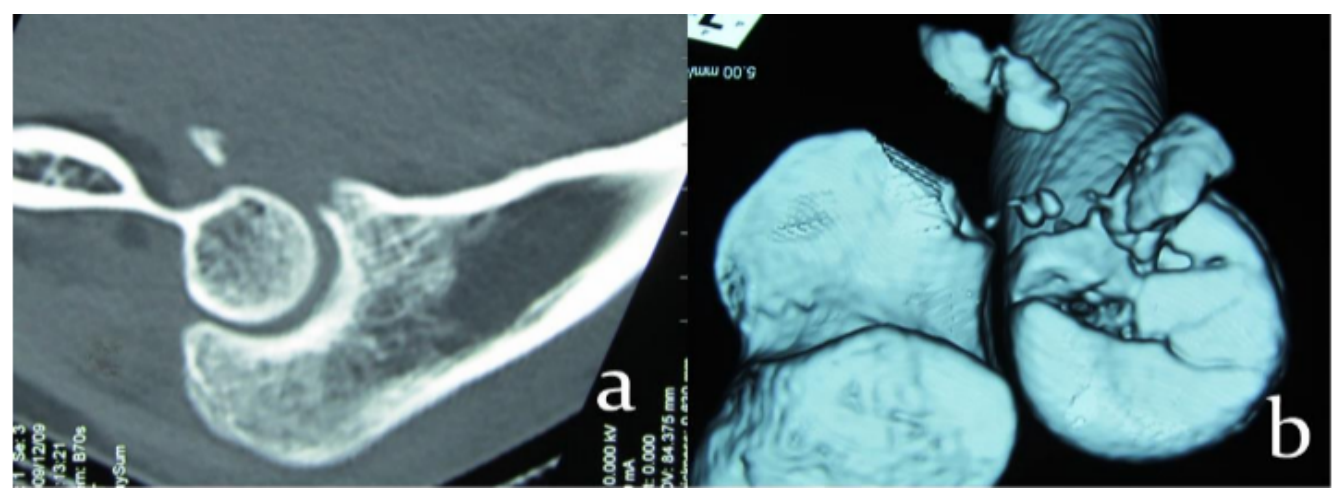

FIGURE 5. Case.14. 29-year-old woman. The so-called "terrible triad injury". The coronoid fracture was lateral, and was a type 1 fracture in the Regan-Morrey and O'Driscoll classifications. 

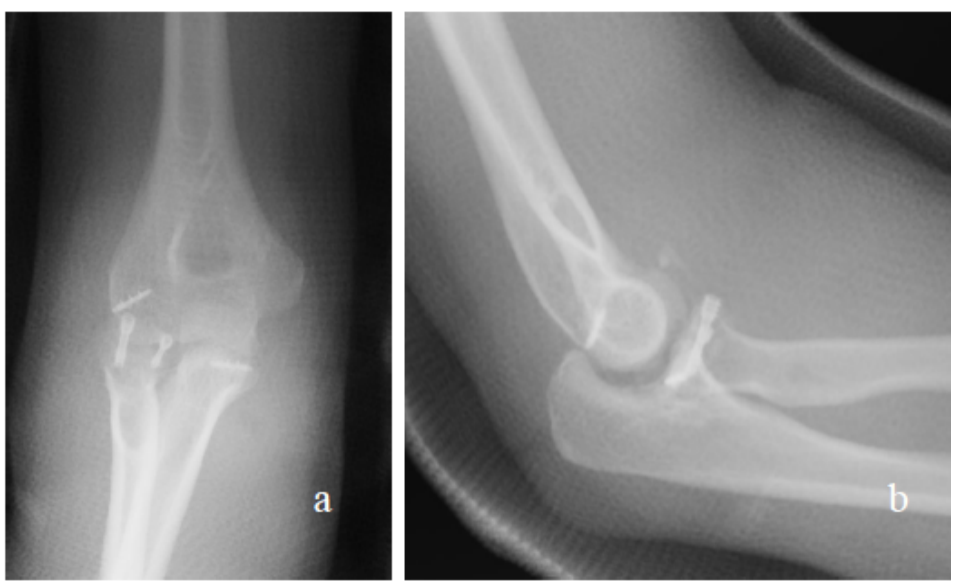

FIGURE 6. Medial collateral ligament (MCL) and LCL repair and screw fixation of the radial head was performed, coronoid fracture was not fixed. Eighteen months after surgery, the arc of elbow motion was $90^{\circ}$ (flexion $120^{\circ}$,extension $-30^{\circ}$ ) and the MEPS was 85 points

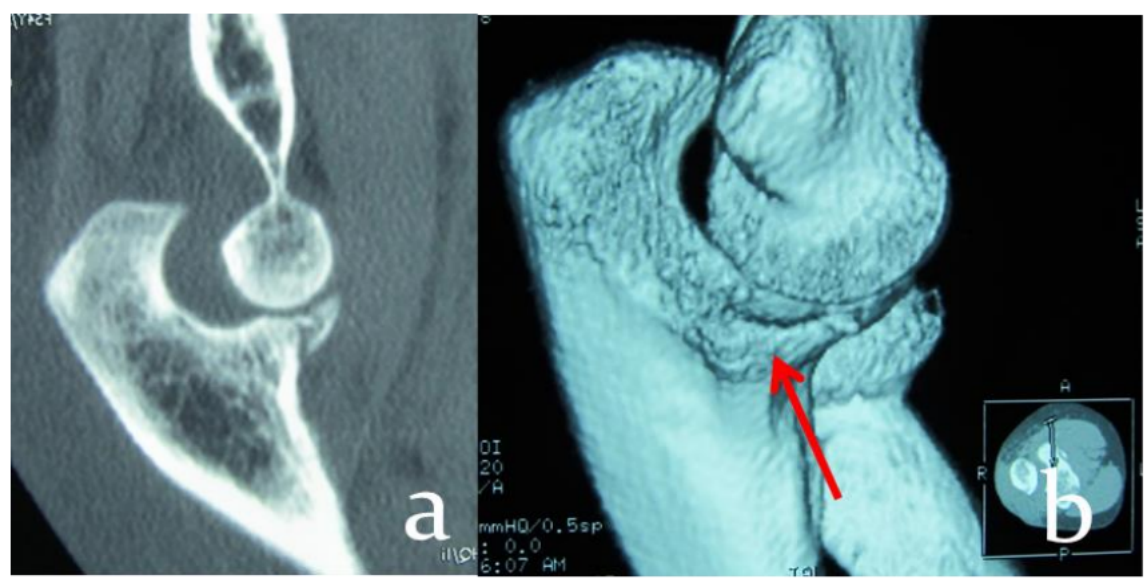

FIGURE 7. Based on fracture fragment height, it was classified as type 1 according to both the ReganMorrey and O'Driscoll classifications (a), but it was classified as type $\mathbf{2}$ in the O'Driscoll classification due to the fracture site (b, arrow).

\section{Discussion}

The coronoid provides a buttress against posterior displacement of the elbow. The medial ridge is important for varus stability of the elbow, while the sublime tubercle contributes to valgus stability because of the MCL attachment to it. Regan and Morrey described 3 coronoid fracture types based on plain lateral X-ray, but this system did not describe avulsion fractures of the sublime tubercle because it did not differentiate medial or lateral articular fractures. Moreover, there is confusion about the definition of "avulsion" size, and this has not been precisely clarified. This was one of the reasons why the treatment for type 2 fractures has been controversial. In considering the operative indications for coronoid fractures, if we regard type 1 as a capsular avulsion fracture, this does not require fixation. This became the classification linked directly with a treatment algorithm. In a macroscopic study, Cage et al ${ }^{3}$ stated that the joint capsule attached $6.4 \mathrm{~mm}$ distal to the tip of the coronoid, but they did not describe the fracture height relative to the total height of the coronoid. Therefore, there was little evidence to substitute a capsular avulsion fracture with the height of the fragment. Schneeberger et al., stated that removal of $30 \%$ of the height of the coronoid in cadavers increased elbow instability with excision of the radial head. Based on those results, Doornberg et al classified type 1 as $<30 \%$ of the total height of the coronoid. We followed this classification, but there was little evidence because $30 \%$ of the total height did not necessarily indicate capsular attachment. Adams et al classified a "tip" fracture as a bony fragment of $<3 \mathrm{~mm}$ in size, and O'Driscoll type 1 (subtype 1) fractures had a fragment that was $<2 \mathrm{~mm}$. Shimura 
et al [8] showed in a microscopic study that the subchondral bone on the coronoid tip, except for the joint cartilage, had a height of approximately $1.9 \mathrm{~mm}$ from the joint capsule attachment. Thus, it might be reasonable that a tip fracture was classified as a bony fragment $<$ $2-3 \mathrm{~mm}$. The O'Driscoll classification was based on the anatomic location of the fracture and size of the fracture fragments, which helped predict associated injuries and injury mechanism. They noted that medial oblique compression fractures could be important to elbow stability because they were associated with VPMRI, despite the fragments being small $[4,2,9]$. Although the O'Driscoll classification is useful, it did not include lateral fractures. Mellema et al. [4] evaluated 110 coronoid fractures by CT and noted that the lateral type was relatively rare. However, lateral fractures surely existed in this study. Because the lateral buttress of the elbow is damaged in terrible triad injuries, both posterior and valgus instability might increase in lateral fractures of the coronoid. In other words, it might be important to fix lateral fractures as well as anteromedial fractures. Historically, lateral fractures have not been regarded as important. Adams et al. [3] evaluated $52 \mathrm{CT}$ scans and classified 5 types of pathoanatomic coronoid fracture patterns including anterolateral fractures. They observed that the anterolateral type occurred in $7 \%$ of cases. The incidence of lateral fractures was $29 \%$ in our study. This is because of the possibility that we judged the O'Driscoll type 2-2 as a lateral fracture, since this type was thought to contain a part of the lateral facet of the coronoid. Moreover, they noted that all anterolateral fractures involved concomitant proximal radius fractures, but there were some lateral-type fractures without an accompanying radial head fracture. We estimated that the force of posterior dislocation was directed more laterally and resulted in a lateral fracture of the coronoid process in terrible triad injuries, via the same mechanism as a bony Bankart lesion in a shoulder dislocation. However, we found that medial fractures were more common in terrible triad injuries in this study. Reichel et al. [10] showed that most fractures were similar to the midtransverse fracture described by Adams et al in terrible triad injuries. This suggested that terrible triad injuries were caused by a complicated injury mechanism. Doornberg et al. [11] reported a detailed association between the injury pattern and associated coronoid fracture pattern. There were some problems with applying the O'Driscoll classification in this study. According to the O'Driscoll classification, AMF fractures were defined as type 2 even if the fragment was a tip fracture and was one that was usually defined as type 1 (FIGURE 7a, b). In this case, the coronoid fracture was a medial, and the ratio of the fragment to the total height was $25 \%$. It was classified as type 1 according to the Regan-Morrey classification. With regard to fragment height, it was also classified as type 1 according to the O'Driscoll classification, but also as type 2 in this classification because of the fracture site. Repair of the MCL and LCL as well as fixation of the radial head fracture was performed, but the coronoid fracture was not fixed in this case. Eight months after surgery, the MEPS was 100 points. Out of the 35 cases in our study, there were 10 cases similar to the case mentioned above, and the outcomes were good. O'Driscoll described that AMF fractures lead to VPMRI of the elbow if left untreated, despite the small size of the fragments, but this requires further examination. Moreover, there were some anterolateral fractures that were not described in the O'Driscoll classification, such as the one shown in FGURE 5b. We reviewed 35 coronoid fractures in detail, and believe that neither the Regan-Morrey or O'Driscoll classifications are adequate to determine a treatment algorithm. The treatment of coronoid fractures has been challenging [12-19], and it is important to perform a multi-component examination, including bony evaluation with 3D CT, evaluation of ligamentous injury with MRI, and an assessment of elbow instability under anesthesia [17] As for clinical outcomes, the average MEPS was 94.8 points (range, 70-100 points), and there were no significant differences in MEPS between the groups. The scores in this series were nearly as high as in a previous report $[16,18]$ and were likely relatively high because of the rough divisions in the MEPS system. However, the outcome scores of the 4 cases of lateral coronoid fractures with accompanying radial head fractures were low. Thus, lateral fractures might be important as well as anteromedial fractures. This study had several limitations. First, the number of cases was small, and this may have led to inadequate detection of differences in outcomes and in the quantity of medial versus lateral fractures. Second, CT scans were not performed consistently (in 3 cases CT scans were not found). Third, because 
the coronoid fragments were displaced or comminuted, it was very difficult to measure the exact height of the fracture fragments, and their size may have been overestimated or underestimated. There have been no reports on the comparison of outcomes following medial and lateral coronoid fractures, and our findings may help clarify treatment decisions. However, larger studies are needed to estimate coronoid fracture patterns, and future research should evaluate the importance of lateral coronoid fractures. Classification systems should be devised that take lateral coronoid fractures into account to better guide treatment decisions.

\section{Conclusions}

We evaluated 35 cases of coronoid fractures. There were more medial than lateral fractures. The total height of the coronoid averaged 22.2 $\mathrm{mm}$. The average height of the coronoid fracture fragments was $6.5 \mathrm{~mm}$, which corresponded to an average of $29.8 \%$ of the total height of the coronoid. Medial fractures were also more common in terrible triad injuries, which was contrary to our hypothesis. The average of MEPS of lateral coronoid fractures with accompanying radial head fractures were relatively low, but there were no significant differences in MEPS between medial and lateral fracture groups.

\section{Acknowledgment}

We thank Peter Mittwede, MD, PhD, from Edanz Group (www.edanzediting.com/ac) for editing a draft of this manuscript.

\section{Disclaimer}

None of the authors, their immediate families, or any research foundations with which they are affiliated received any financial payments or other benefits from any commercial entity related to the subject of this article. 


\section{REFERENCES}

Regan WD, Morrey BF. Coronoid process and Monteggia fractures. The elbow and its disorders. 3rd ed. Philadelphia: WB Saunders. 419-424 (2009).

O'Driscoll SW, Jupiter JS, Cohen MS, Ring D, Mckee MD. Difficult elbow fractures: Pearls and pitfalls. Instr. Course Lect. 52, 113-134 (2003).

Adams JE, Sanchez-Sotelo J, Kallina CF, Morrey BF, Steinmann SP. Fracture of the coronoid: morphology based upon computer tomography scanning. J. Shoulder Elbow Surg. 21(6), 782-788 (2012).

Mellema JJ, Doornberg JN, Dyer GS, Ring D. Distribution of coronoid fracture lines by specific patterns of traumatic elbow instability. J. Hand Surg. Am. 39(10), 2041-2046 (2014).

Doornberg JN, Duijn J, Ring D. Coronoid fracture height in terrible-triad injuries. J. Hand Surg. Am. 31(5), 794797 (2006).

Schneeberger AG, Sadowski MM, Jacob HA. Coronoid process and radial head as posterolateral rotatory stabilizers of the elbow. J. Bone Joint Surg. Am. 86(5), 975-82 (2004).

Garrigues GE, Wray WH, Lindenhovius AL, Ring DC, Ruch DS.
Fixation of the coronoid process in elbow fracture-dislocations. J. Bone Joint Surg. Am. 93(20), 1873-1881 (2011).

Haruhiko S, Akimoto N, Hisayo N, Hitomi F, Junya I, et al. Joint capsule attachment to the coronoid process of the ulna: an anatomic study with implications regarding the type 1 fractures of the coronoid process of the O'Driscoll classification. J. Shoulder Elbow Surg. 25(9), 1517-1522 (2015).

Sanchez-Sotelo J, O'Driscoll SW, Morrey BF. Medial oblique compression fracture of the coronoid process of the ulna. J. Shoulder Elbow Surg. 14(1), 60-64 (2005)

Reichel LM, Milam GS, Hillin CD, Reitman CA. Osteology of the coronoid process with clinical correlation to coronoid fractures in terrible triad injuries. J. Shoulder Elbow Surg. 22(3), 323-328 (2013).

Doornberg JN, Ring DC. Coronoid fracture patterns. J. Hand Surg. Am. 31(1), 45-52 (2006).

Budoff JE. Coronoid fractures. J. Hand Surg. Am. 37, 2418-2423 (2012).

Gray AB, Alolabi B, Ferreira LM, Athwal GS, King GJ, et al. The effect of coronoid prosthesis on restoring stability to the coronoid-deficient elbow: A biomechanical study. J. hand Surg. Am. 38(9), 1753-1761 (2013).
Haruhiko S, Akimoto N, Hisayo N, Hitomi F, Junya I, et al. Joint capsule attachment to the coronoid process of the ulna: an anatomic study with implications regarding the type 1 fractures of the coronoid process of the O'Driscoll classification. J. Shoulder Elbow Surg. 25(9), 517-522 (2016).

Mazhar FN, Jafari D, Mirzaei A. Evaluation of functional outcome after nonsurgical management of terrible triad injuries of the elbow. J. Shoulder Elbow Surg. 26(8), 1342-1347 (2017).

Park SM, Lee JS, Jung JY, Kim JY, Song KS. How should anteromedial coronoid facet fracture be managed? A surgical strategy based on O'Driscoll classification and ligament injury. J. Shoulder Elbow Surg. 24(1), 74-82 (2015).

Rhyou IH, Kim KC, Lee Ji-Ho, Kim SY. Strategic approach to O'Driscoll type 2 anteromedial coronoid facet fracture. J. Shoulder Elbow Surg. 23(7), 924-932 (2014).

Ring D, Horst TA. Coronoid fractures. J. Orthop Trauma 29(10), 437-440 (2015).

Guitton TG, Kinaci A, Ring D. Diagnostic accuracy of 2- and 3-dimensional computed tomography and solid modeling of coronoid fractures. J. Shoulder Elbow Surg. 22(6), 782-786 (2013). 